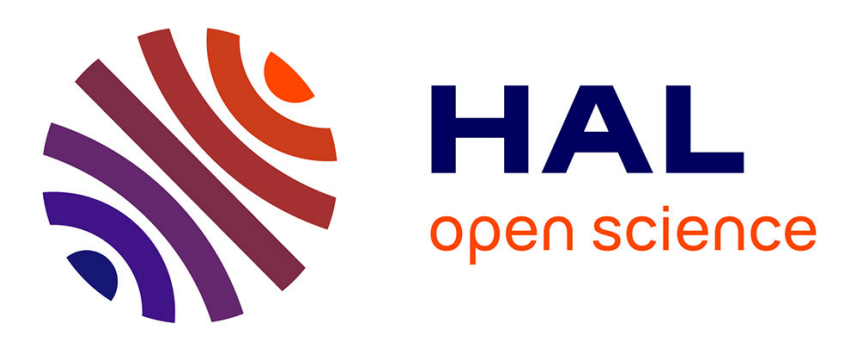

\title{
Shape change of the flexible polymer in solution with increasing concentration
}

B. Farnoux, M. Daoud, D. Decker, G. Jannink, R. Ober

\section{To cite this version:}

B. Farnoux, M. Daoud, D. Decker, G. Jannink, R. Ober. Shape change of the flexible polymer in solution with increasing concentration. Journal de Physique Lettres, 1975, 36 (2), pp.35-39. 10.1051/jphyslet:0197500360203500 . jpa-00231148

\section{HAL Id: jpa-00231148 https://hal.science/jpa-00231148}

Submitted on 1 Jan 1975

HAL is a multi-disciplinary open access archive for the deposit and dissemination of scientific research documents, whether they are published or not. The documents may come from teaching and research institutions in France or abroad, or from public or private research centers.
L'archive ouverte pluridisciplinaire HAL, est destinée au dépôt et à la diffusion de documents scientifiques de niveau recherche, publiés ou non, émanant des établissements d'enseignement et de recherche français ou étrangers, des laboratoires publics ou privés. 


\title{
SHAPE CHANGE OF THE FLEXIBLE POLYMER IN SOLUTION WITH INCREASING CONCENTRATION
}

\author{
B. FARNOUX, M. DAOUD, D. DECKER (*), G. JANNINK and R. OBER $\left(^{* *}\right)$ \\ Service de Physique du Solide et de Résonance Magnétique \\ Centre d'Etudes Nucléaires de Saclay, BP 2, 91190 Gif-sur-Yvette, France
}

(Reçu le 28 octobre 1974, accepté le 10 décembre 1974)

\begin{abstract}
Résumé. - Une expérience de diffusion de neutrons par des mélanges de polystyrènes deutériés et protonés en solution dans le sulfure de carbone a permis d'observer l'évolution de la configuration de la chaîne en fonction de la concentration. La dépendance en concentration de la fonction de corrélation de paire de segments appartenant à une même chaîne est décrite à l'aide de l'exposant de volume exclu.
\end{abstract}

\begin{abstract}
A few deuterated polystyrene chains are dispersed in a solution of protonated polystyrene and carbone disulfide. The neutron scattered intensity is measured at several concentrations of protonated chains. Already in the semidilute range, there is a striking contrast with the results obtained at equal concentrations in fully deuterated solutions. The dependence of the pair correlation function on concentration is discussed in terms of the excluded volume exponent.
\end{abstract}

The excluded volume exponent $v$ has been measured [1] in dilute solutions $(v \simeq 3 / 5)$ and in the bulk state $(v=1 / 2)$, and the question arises as to what happens in the intermediate situation when the polymer concentration $C$ varies from zero to $d$, the polymer density. Such a problem is typical of a situation in which there is a cross over region for the critical exponents. The parameter is here the concentration $C$.

The experimental answer can be given by the observation of the single chain in solutions with increasing polymer concentration. This requirement is nearly ideally achieved experimentally by observing the scattering of neutrons from mixtures of deuterated and protonated chains dispersed in a solvant, such that the contrast between protonated chains and solvant is very small compared to the contrast between deuterated chains and solvant and can be neglected.

The neutron intensity scattered by deuterated polystyrene (concentration $C_{\mathrm{D}}$ ) dispersed in solutions of protonated polystyrene (concentration $C_{\mathrm{p}}$ ) and carbon disulfide was therefore measured at different values of $C_{\mathrm{D}}$ and $C_{\mathrm{P}}$ (Table I). In a preliminary experiment the scattering law was tested for $C_{\mathrm{P}}=0$ and $C_{\mathrm{D}}>C^{*}$, the concentration at which the chains begin to overlap. For this experiment, the scattering amplitude is written as $S_{\mathrm{c}}^{T}(q)$, where $q$ is the momentum transfer. In the main experiments, the scattering law was measured for $C_{\mathrm{D}}<C^{*}$ and

$$
C=C_{\mathrm{P}}+C_{\mathrm{D}}>C^{*} \text {. }
$$

(*) CRM, 6, rue Boussingault, Strasbourg.

$\left({ }^{* *}\right)$ Collège de France, 11, place Marcellin-Berthelot, Paris.
Here, analogous to the above, $S_{\mathrm{c}}^{L}(q)$, denotes the scattering amplitude. The experiments were carried out in the intermediate momentum range

$$
\left(N^{1 / 2} l\right)^{-1}<q<l^{-1}
$$

where $l$ is the step length and $N$ is the number of steps per chain. Earlier results $[2,3]$ showed that in range (1) the theoretical expression

$$
S_{\mathrm{c}}^{T}(q)=\frac{A C}{q^{2}+\xi^{-2}}
$$

was verified where $A$ is a constant and $\xi$ is the screening length

$$
\xi=\left(\frac{12 C v \mathfrak{A}}{l^{2} m}\right)^{-1 / 2}
$$

in which $v$ is the excluded volume parameter, $\mathcal{A}$ the Avogadro number, and $m$ is the molecular weight of a segment. Form (2) will serve as a reference in the interpretation of the experiments, for which the analytical form $S_{\mathrm{c}}^{L}(q)$ is not known. In fact $S_{\mathrm{c}}^{L}(q)$ is known in the two limits $C \rightarrow 0$ and $C=d$, where it is

$$
S_{\mathrm{c}}^{L}(q)=\frac{B C}{q^{1 / v}+O\left(\frac{1}{N l^{1 / v}}\right)} .
$$

Here $v$ takes the value $3 / 5$ for $C \rightarrow 0$, and $1 / 2$ for $C=d . B$ is a constant. An expression similar to eq. (4) is expected to be valid in the above mentioned 
TABLE I

\begin{tabular}{|c|c|c|c|c|c|c|}
\hline \multirow{2}{*}{$\begin{array}{c}\text { Sample } \\
-\end{array}$} & $\begin{array}{l}\text { Molecular } \\
\text { weight }\end{array}$ & $\begin{array}{c}\text { Radius } \\
\text { of giration } \\
\AA\left({ }^{a}\right)\end{array}$ & $\begin{array}{c}C^{*} \\
\mathrm{~g} / \mathrm{cm}^{3}\end{array}$ & $\begin{array}{r}\text { Deute } \\
\text { Co } \\
\text { and }\end{array}$ & $\begin{array}{l}\text { rated polymer } \\
\text { chain } \\
\text { ncentration } \\
\text { environment } \\
/ / \mathrm{cm}^{3}(b)\end{array}$ & $\begin{array}{c}\text { Transmission } \\
\text { (thickness) }\end{array}$ \\
\hline & $5 \times 10^{5}$ & $\overline{216}$ & $\overline{026}$ & 0005 & $\overline{C s}$ & $0, \overline{1}(1 \mathrm{~cm})$ \\
\hline $\begin{array}{l}\text { A } \\
\text { B }\end{array}$ & - & - & - & 0.04 & $\begin{array}{l}\mathrm{CS}_{2} \\
\mathrm{CS}_{2}\end{array}$ & $0.906(1 \mathrm{~cm})$ \\
\hline $\mathrm{C}$ & - & - & - & 0.005 & $\begin{array}{l}\text { solution of } \\
\text { protoned } \\
\text { polystyrene } \\
\text { in } \mathrm{CS}_{2} \\
C_{\mathrm{T}}=0.04\end{array}$ & $0.807(1 \mathrm{~cm})$ \\
\hline D & - & - & - & 0.075 & $\mathrm{CS}_{2}$ & $0.858(1 \mathrm{~cm})$ \\
\hline $\mathrm{E}$ & - & - & - & 0.005 & $\begin{array}{l}\text { solution of } \\
\text { protoned } \\
\text { polystyrene } \\
\text { in } \mathrm{CS}_{2} \\
C_{\mathrm{T}}=\mathbf{0 . 0 7 5}\end{array}$ & $0.847(0.5 \mathrm{~cm})$ \\
\hline F & $1.1 \times 10^{6}$ & 568 & 0.014 & 0.01 & $\begin{array}{l}\text { solution of } \\
\text { protoned } \\
\text { polystyrene } \\
\text { in } \mathrm{CS}_{2} \\
C_{\mathrm{T}}=0.50\end{array}$ & $0.696(0.2 \mathrm{~cm})$ \\
\hline G & $1.1 \times 10^{6}$ & - & - & 0.02 & $\begin{array}{l}\text { bulk of } \\
\text { protoned } \\
\text { polystyrene }\end{array}$ & $0.921(0.1 \mathrm{~cm})$ \\
\hline
\end{tabular}

$\left({ }^{a}\right)$ Values obtained from the table VI of macromolecules (to appear in 1974).

$\left({ }^{b}\right)$ The molecular mass of the protonated polystyrene are the same than the deuterated one.

concentration range. However the momentum range for which the exponent $v$ takes a definite value may not cover the entire range of $q$ values (1). The problem is to determine the momentum dependence of $S_{\mathrm{c}}^{L}(q)$ for $C^{*}<C<d$ from the experimental data reported in this letter (Fig. 1). These data were obtained with the small angle scattering apparatus at the neutron guide exit of reactor EL3 at Saclay. The wave-length of the incident beam, selected by a crystalline monochromator was $\lambda=4.62 \pm 0.04 \AA$, and a divergence of less than 0.3 degree was achieved by means of a collimator. The scattered intensity was recorded for angles $\theta$ so chosen that the momentum transfer $q=4 \pi / \lambda \sin \theta / 2$ ranged from $10^{-2}$ to $10^{-1} \AA^{-1}$, satisfying inequality (1). The intensity scattered by the labelled chains was obtained by substracting the intensity scattered by the solvant (i.e. carbon disulfide plus protonated chains) from the total intensity. A study of the multiple scattering effects made for a previous experiment [1], had shown that these did not interfer with the results.

Before discussing the experimentally observed results we consider representations of the scattered intensity versus momentum transfer which are appropriate to determine the values of $v$ in interval (1). The interpolation formula will essentially be eq. (4), in which however, a broadening $D$ due to the finite

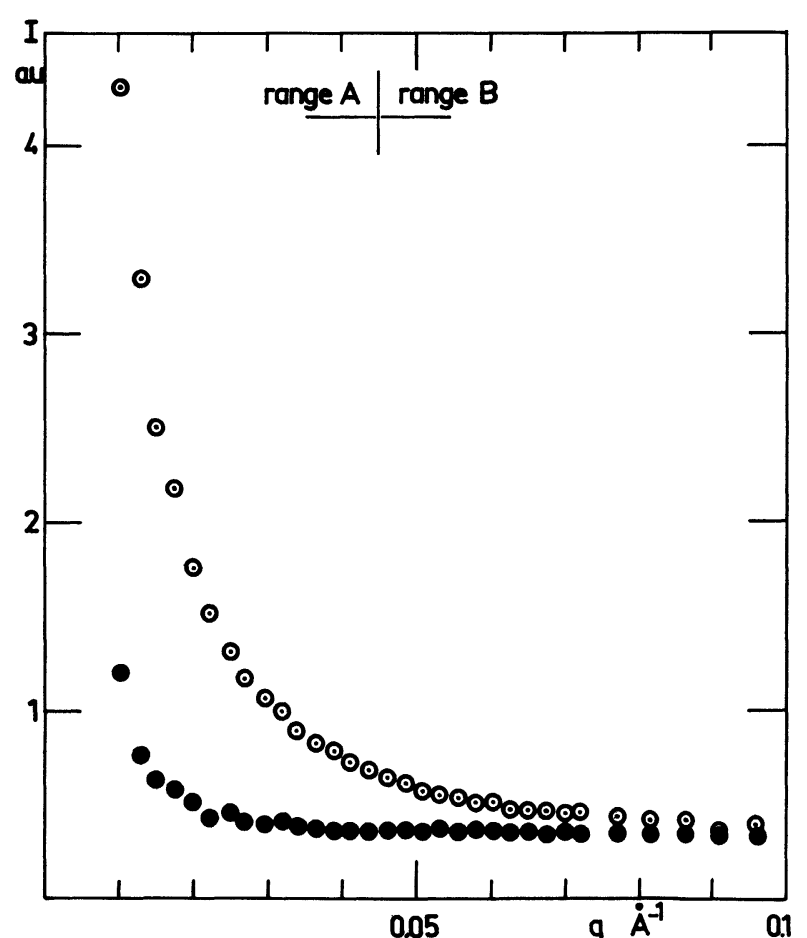

FIG. 1. - Scattered intensity as a function of momentum transfer $q$. Sample F. The lower curve (closed circles) is the background due to solvent, container and incoherent scattering of the solute molecules. This curve is subtracted from the upper one to give the useful signal. The momentum range is divided into two parts corresponding to appropriate representations of the results. (See text.) 
concentration $C_{\mathrm{D}}$ of deuterated chains, is allowed to appear

$$
S_{\mathrm{c}}^{L}(q)=\frac{B}{q^{1 / v}+D+O\left(\frac{1}{N l^{1 / v}}\right)}
$$

A) In the limit $q \rightarrow\left(N^{1 / 2} l\right)^{-1}$, the most appropriate representation of the experimental data is $\left(S_{\mathrm{c}}^{L}(q)\right)^{-1}$ versus $q^{2}=X$. In case the deuterated chains behave as isolated self avoiding chains in a good solvent, then

$$
\left(S_{\mathrm{c}}^{L}(q)\right)^{-1}=X^{5 / 6}, \quad X>(N l)^{-2} .
$$

The curvature in (5) is the more pronounced the nearer $X$ is allowed to approach zero. In the limit of an infinite polymer chain, curve (5) extrapolates to a vertical tangent.

If, on the contrary, the deuterated chains behave as free coils, $\left(S_{\mathrm{c}}^{L}(q)\right)^{-1}$ depends linearly on $X$.

A similar representation consists in plotting the results $\left(S_{\mathrm{c}}^{L}(q)\right)^{-1}$ versus $q^{5 / 3}=Y$. The free coil model is represented by

$$
\left(S_{\mathrm{c}}^{L}(q)\right)^{-1}=Y^{6 / 5}, \quad Y>(N l)^{-5 / 3}
$$

whereas the chain with self excluded volume interaction yields

$$
\left(S_{\mathrm{c}}^{L}(q)\right)^{-1}=Y, \quad Y>(N l)^{-5 / 3} .
$$

$B)$ In the upper part of range (1), a convenient representation of the experimental data is $S_{\mathrm{c}}^{L}(q)$ versus $Z=1 / q^{2}$. More precisely,

$$
S_{\mathrm{c}}^{L}(q)=\frac{Z^{1 / 2 v}}{1+Z^{1 / 2 v}\left\{D+O\left(\frac{1}{N l^{1 / v}}\right)\right\}}
$$

If the exponent $v$ is strictly greater than $1 / 2$ (for instance $v=3 / 5$ ), curve (7) displays a curvature. On the other hand, if $v=1 / 2$ this function is linear provided that $\left\{D+O\left(1 / N l^{1 / v}\right)\right\}$ is small enough. i.e. smaller than $Z_{\max }$.

C) The $\log S_{\mathrm{c}}^{L}(q)$ versus $\log q$ representation used in reference [1] is not appropriate for the investigation of the lower part of range (1) because of the broadening terms $\xi^{-2}$ and $D$, respectively, in (2) and in (4'). In the upper part of range (1), this representation is as $\operatorname{good}$ as $B$ ) and yields identical results.

With these considerations in mind, we shall determine, from examination of the scattered intensity curves, which of the two values of the exponent $v$ provides the best fit with the data, in dividing perhaps arbitrarily momentum range (1) into two intervals. For the semi-dilute solutions, we shall observe the limit $q \rightarrow(N l)^{-1}$, since it is expected that the concentration effects first modify the lower part of (1), as $C$ increases. In figures 2 and $3,\left(S_{\mathrm{c}}^{L}(q)\right)^{-1}$ and $\left(S_{\mathrm{c}}^{T}(q)\right)^{-1}$

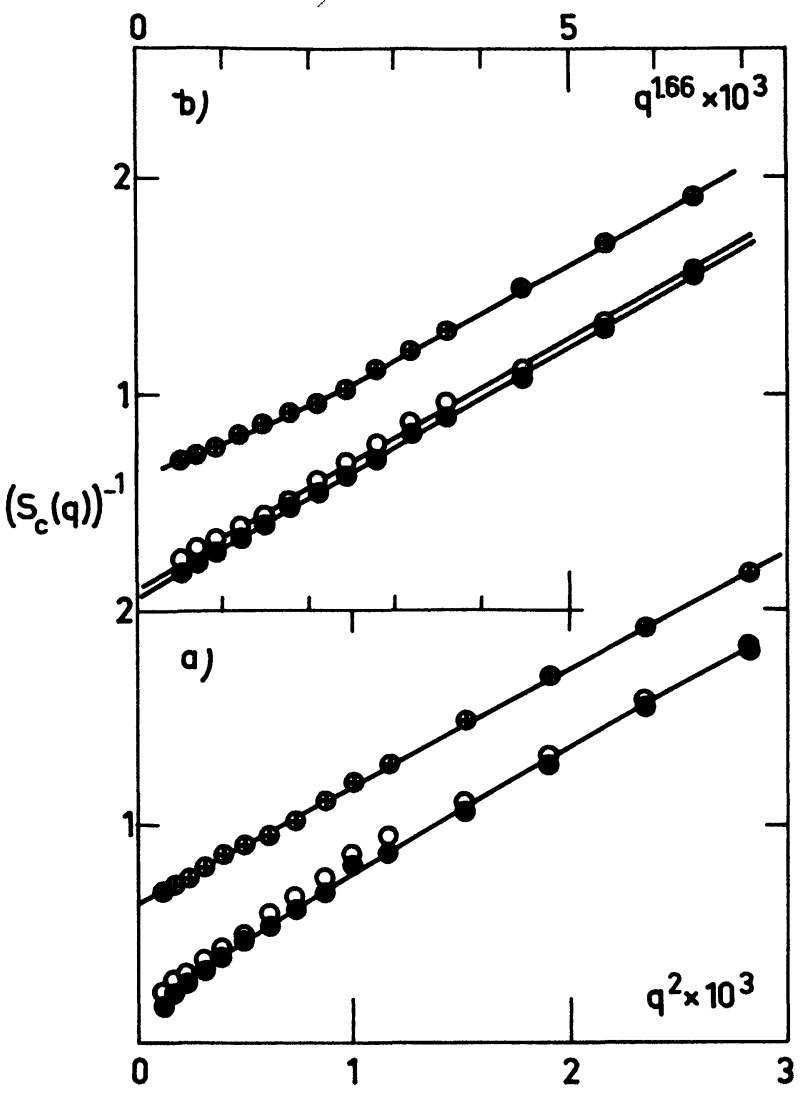

FIG. 2. - Inverse scattering laws $\left(S_{c}^{L}(q)\right)^{-1}$ (closed circles) and $\left(S_{\mathrm{c}}^{\mathrm{T}}(q)\right)^{-1}$ (crossed circles) as a function of $\left.a\right) q^{2}$ and of $\left.b\right) q^{5 / 3}$, for $C=4 \times 10^{-2} \mathrm{~g} \cdot \mathrm{cm}^{-3}$. Also represented is the scattering by a dilute solution $\left(S_{0}^{T}(q)\right)^{-1}$ (open circles).

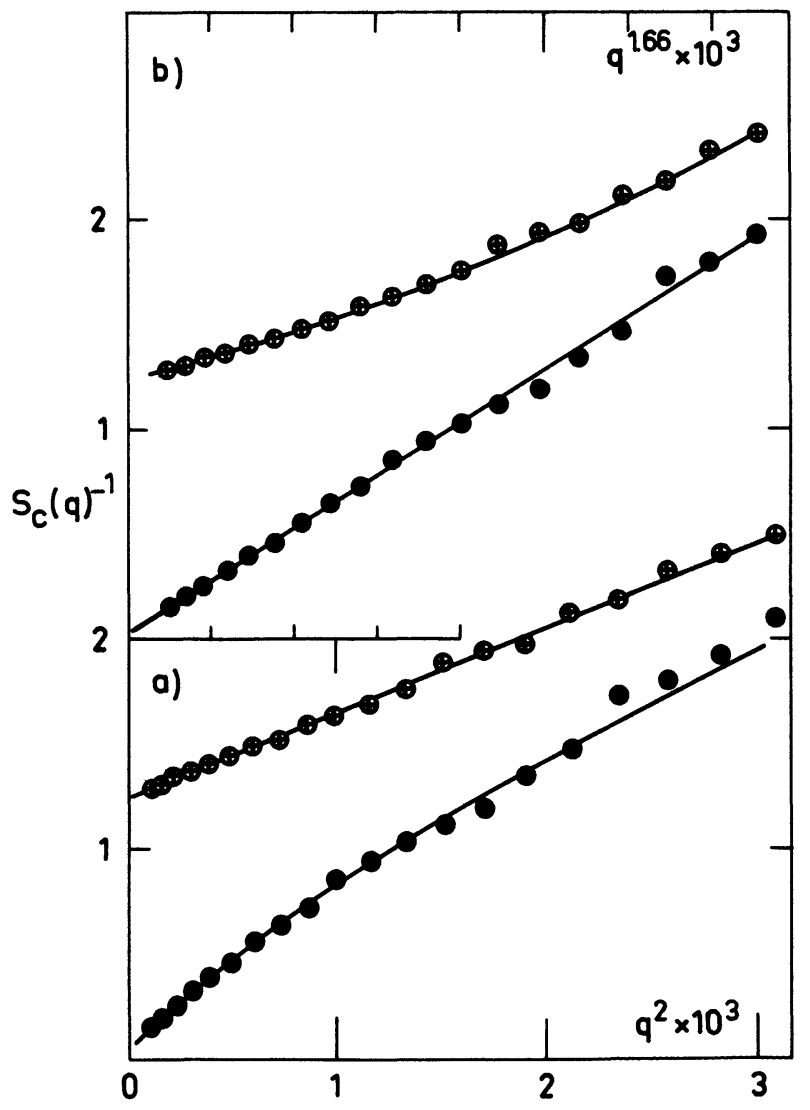

FIG. 3. - Inverse scattering laws $\left(S_{\mathrm{c}}^{L}(q)\right)^{-1}$ (closed circles) and $\left(S_{\mathrm{c}}^{T}(q)\right)^{-1}$ (crossed circles) as a function of $\left.a\right) q^{2}$ and of $\left.b\right) q^{5 / 3}$, for $C=7.5 \times 10^{-2} \mathrm{~g} . \mathrm{cm}^{-3}$. 
are displayed in the two representations $q^{2}=X$ and $q^{3 / 5}=Y$. The concentrations $C$ are respectively $4 \times 10^{-2} \mathrm{~g} . \mathrm{cm}^{-3}$ (sample B, C in table I) and $7.5 \mathrm{~g} \mathrm{.} \mathrm{cm}^{-3}$ (sample D, E). Also shown in figure 2 is the scattering $S_{\mathrm{o}}^{T}$ by a very dilute solution (sample $\mathrm{A}$ ). The opposition between $S_{\mathrm{c}}^{T}$ and $S_{\mathrm{c}}^{L}$ is obvious and the curvature of $S_{\mathrm{c}}^{L}$ appears clearly in figs. $(2 a)$ and ( $\left.3 a\right)$. On the contrary, $S_{\mathrm{c}}^{L}$ and $S_{\mathrm{o}}^{T}$ show identical behaviours. At these two finite concentrations $\left(C>C^{*}\right)$, the momentum range over which $v=3 / 5$ holds true covers most of range (1), as in the case of very dilute solutions (sample A).

At the higher concentration $C=50 \times 10^{-2} \mathrm{~g} \cdot \mathrm{cm}^{-3}$, the picture is different (Fig. 4a). The inverse scattering law $\left(S_{\mathrm{c}}^{L}\right)^{-1}$ as a function of $q^{2}$ does not indicate the curvature observed in the semi-dilute solutions (Figs. $2 a$ and $3 a$ ).
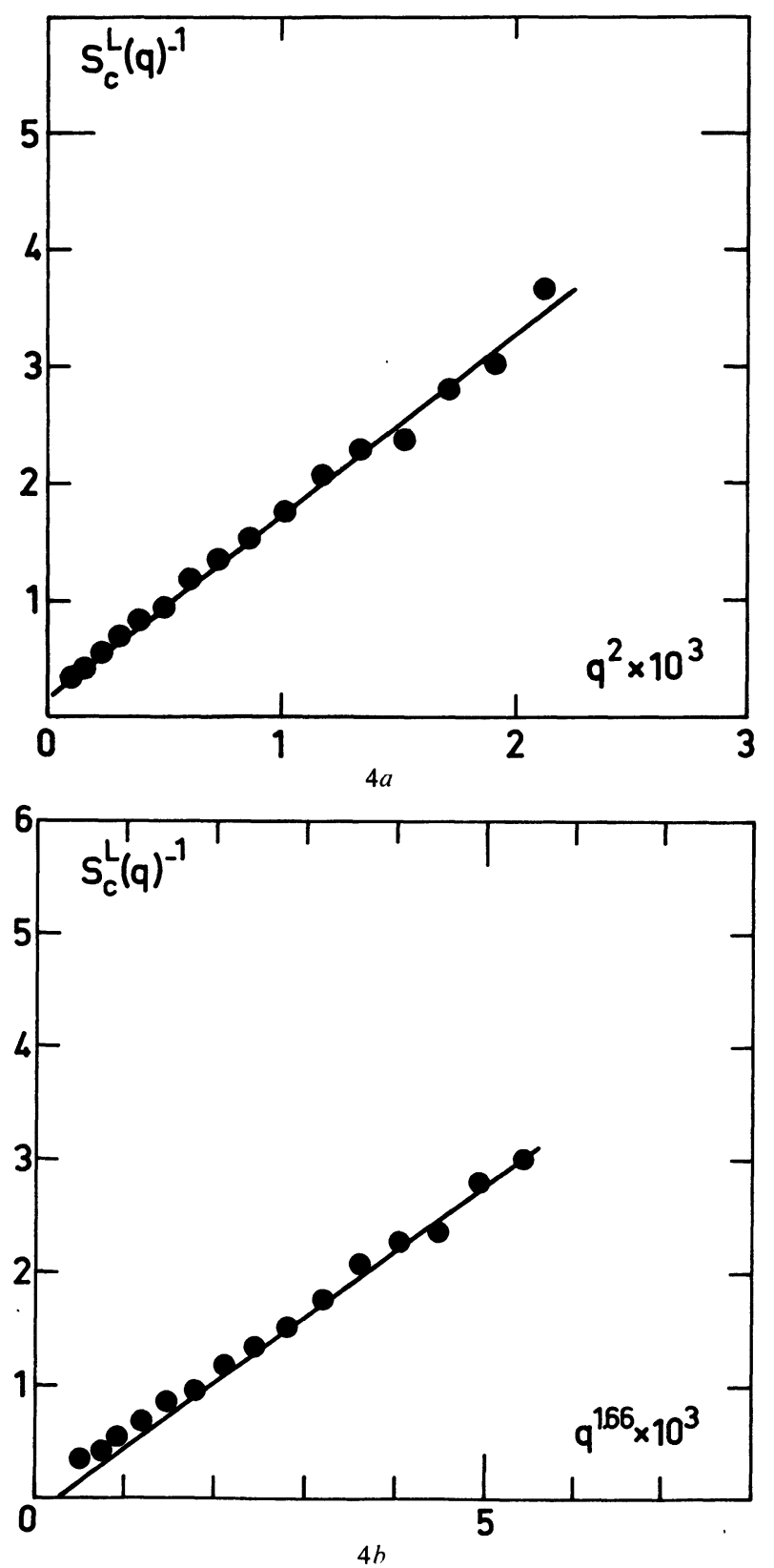

Fig. 4. - Inverse scattering law $\left.\left(S_{\mathrm{c}}^{L}(q)\right)^{-1} a\right)$ as a function of $q^{2}$, $b$ ) as a function of $q^{5 / 3}$, for $C=50 \times 10^{-2} \mathrm{~g} \cdot \mathrm{cm}^{-3}$. In $b$ ) a tangent is drawn to help visualize the curvature.
In contrast a curvature exists in the $q^{5 / 3}$ representation (Fig. $4 b$ ), which is not very strong, but nevertheless undeniable by considering the intercept of the tangent with the $Y$ axis. We conclude that here, i.e. in the limit $q \rightarrow(N l)^{-1}$, the excluded volume exponent for the single chain takes the value $v=1 / 2$. This result encouraged us to investigate carefully the upper part of momentum range (1). In figure 5, the scattering law for $C=50 \times 10^{-2} \mathrm{~g} . \mathrm{cm}^{-3}(5 a)$ and $C=d(5 b)$ is displayed as a function of $1 / q^{2}$. The bulk picture serves here as a reference, since it is already known from earlier experiments that the value $v=1 / 2$ holds true over the entire range (1). This is not the case at $C=50 \times 10^{-2} \mathrm{~g} . \mathrm{cm}^{-3}$ which displays a curvature in the $1 / q^{2}$ representation. This curvature cannot be attributed to the term $D$ in (7); namely the highest possible value of $D$ which is the inverse squared screening length associated with a polymer concentration equal to $C_{\mathrm{D}}\left(D \sim 10^{-4} \AA^{-2}\right)$. The curvature is in fact due to the value of the excluded volume exponent $v=3 / 5$.

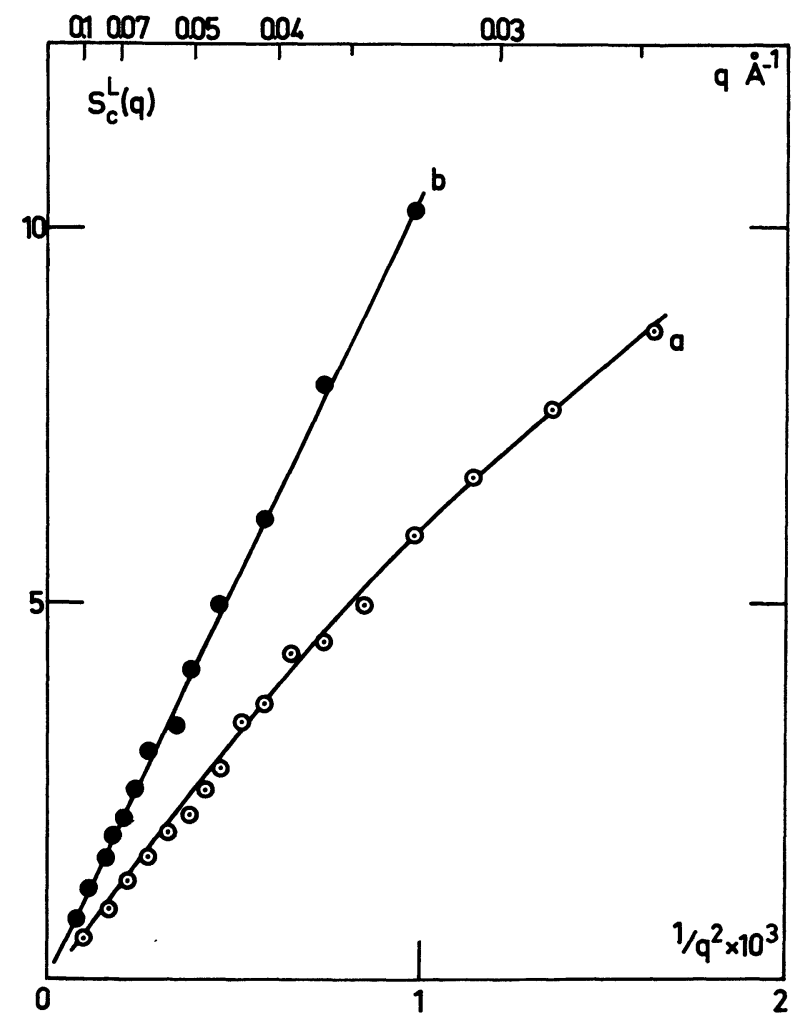

FIG. 5. - Scattering law $S_{\mathrm{c}}^{L}(q)$ as a function of $1 / q^{2}$ for

a) $C=50 \times 10^{-2} \mathrm{~g} \cdot \mathrm{cm}^{-3}$ and $\left.b\right) C=d$.

The earlier picture given in reference [1] may now be completed in the following way.

1) Semi-dilute solutions. - The effect of the uniform distribution of the chain segments in the solution is borne out by the Lorentzian behaviour of the total scattering law $S_{\mathrm{c}}^{T}(q)$ (i.e. all segments coherently scatter). In contrast, the scattering law for the single chain $S_{\mathrm{c}}^{L}(q)$ (i.e. a few chains are deuterated) still 
reflects the self excluded volume effect $v=3 / 5$ over most of the intermediate momentum transfer range (1).

2) Concentrated solutions. - The behaviour of $S_{\mathrm{c}}^{L}$ in the lower part of the momentum range departs from the isolated chain model. The exponent $v=1 / 2$ fits the data in this region. On the contrary, in the upper part of the momentum range the chain still behaves as if its conformation were dominated by its own excluded volume. The exponent is here $v=3 / 5$. Such distinct behaviours lead to a cross-over momentum value $q^{*}$. This momentum increases with concentration. It is however different from zero only for concentrations larger than $10 \times 10^{-2} \mathrm{~g} . \mathrm{cm}^{-3}$.

3) In the bulk state $v=1 / 2$ uniformly over the entire intermediate momentum range. The momentum $q^{*}$ has increased beyond $l^{-1}$.

An intuitive interpretation of result (2) may be given by examination of the force field [4] around the labelled polymer segment. This field $V(r)$ is proportional to the segment density. In the limit $C=0$, this is

$$
V(r)=k T v l^{-2} p(r)
$$

where $p(r)$ is the density of segments for a chain whose first segment is fixed at the origin. $(p(r)$ is equal to the pair correlation function.) As the concentration increases, the segment at the origin is also surrounded by other chains, whose segment density is represented by the horizontal line $\rho$ in figure 6 . At the intersection $r^{*}$, the two densities are equal. For distances $r>r^{*}$, the self interacting potential is strongly screened by the presence of other chains; whereas for $r<r^{*}$, the self excluded volume effect still dominates. A simple derivation shows that

$$
r^{*}=\left(q^{*}\right)^{-1}=\xi\left(\frac{\xi}{l}\right)^{1 / 2}
$$

which is not a very satisfying scaling law from a theoretical point of view, nor does it fit the present observations. However, it satisfies the inequality

$$
l<r^{*}<R
$$

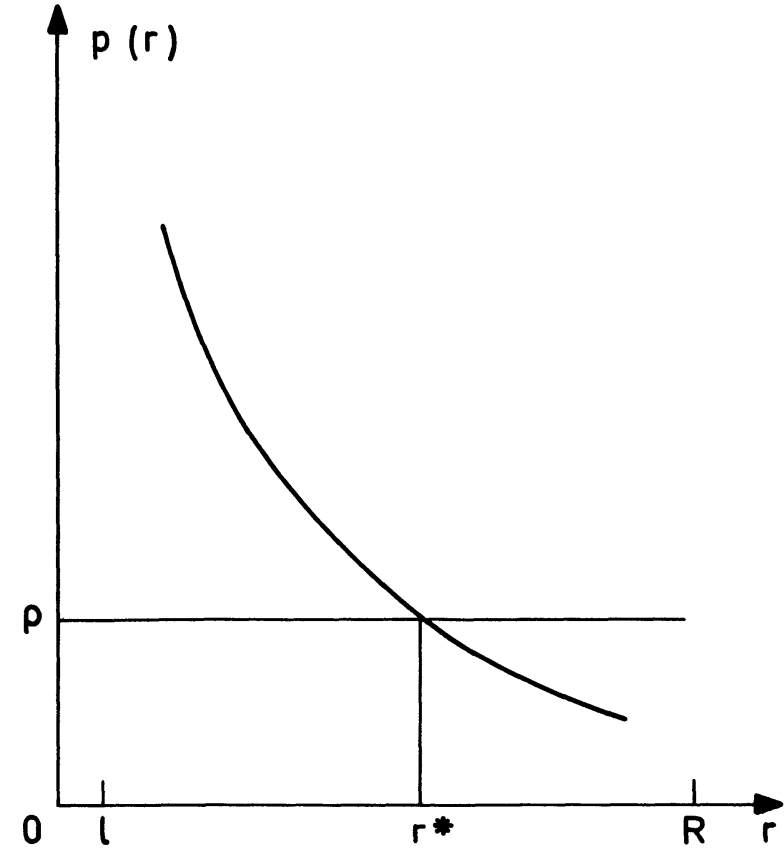

FIG. 6. - Schematic view of the segment densities surrounding the first segment of a chain in the concentrated solution. $a$ ) density of segments belonging to its own chain, $b$ ) density of segments belonging to other chains.

and gives an approximate idea of the cross over line. This idea contradicts the opinion that the index $v$ decreases from the value $3 / 5$ to the value $1 / 2$ as a function of increasing concentration. At a given (high) concentration there is a value $q=q^{*}$ which separates the reciprocal space into two domains. For $q<q^{*}$, the chain has a free coil behaviour $(v=1 / 2)$; for $q>q^{*}$, the chain has an excluded volume behaviour $(v=3 / 5)$. This value of $q^{*}$ moves from $R^{-1}$ to $l^{-1}$ as the concentration increases from the dilute to the bulk state.

Acknowledgments. - We wish to thank Prof. P. G. de Gennes for suggesting and discussing this experiment, Prof. H. Benoit and Dr. J. P. Cotton for many helpful criticisms of the manuscript.

\section{References}

[1] Cotton, J. P., Decker, D., Farnoux, P., Jannink, G., Ober, R., Picot, C., Phys. Rev. Lett. 32 (1974) 1170.

[2] Cotton, J. P., Farnoux, B., Jannink, G., J. Chem. Phys. 57 (1972) 290
[3] Cotton, J. P., Thesis Paris 1973, C.E.A-N-1743.

[4] De Gennes, P. G., Rep. Prog. Phys. 34 (1969) 1253.

[5] Jannink, G., de Gennes, P. G., J. Chem. Phys. 48 (1968) 2260. 